\title{
Knowledge of English Focus Constructions by Saudi Learners of English: Usage-Based Approach
}

\author{
Nadiah Aleraini \\ Princess Nourah bint Abdulrahman University, KSA
}

\begin{abstract}
The current study investigates whether Saudi-Arabic speaking learners of English are sensitive to the information-structure constraints and frequency distribution when dealing with the syntactic means of information highlighting in English. Ninetynine participants of different proficiency levels in English completed an acceptability rating task that asked participants to rate the target constructions in two different contexts eliciting either a narrow focus, in which the use of the target constructions was acceptable (felicitous), or a broad focus in which their use was inacceptable (infelicitous). The findings indicate that participants were sensitive to the contextual effect, as evident from participants' higher acceptability ratings in the felicitous context than the infelicitous context. Moreover, frequency impact was evident in their higher acceptability ratings in the felicitous context for the comparatively frequent constructions. Differences in the perceived acceptability of the target constructions by participants suggest a role for proficiency. All in all, the results obtained in this study supported the general predictions of usage-based approaches to SLA and shed light on the role of cognitive processes in the acquisition of the target constructions.
\end{abstract}

Keywords: focus constructions, frequency, information structure, non-canonical word order, usage-based.

\section{Introduction}

Successful second language acquisition and mastery comprise a recognition of different grammatical constructions in the target language and an ability to identify their appropriate contextual uses. While learners at an advanced level of language proficiency are capable of producing written production that is free from grave grammatical errors, they often face problems when trying to package information in the written mode in English (Carroll et al. 2000; Callies 2009; Sorace 2011). The appropriate use of highly optional syntactic means of information structuring by L2 users requires knowledge of the mapping of discourse constraints on word-order (Hopp 2009). In English, these syntactic means include the focus constructions related to object focus, specifically the itcleft, $w h$-cleft, reverse $w h$-cleft ( $r w h$-cleft) and preposing. Given that these constructions are not highly frequent in either written or spoken L1 English, let alone in learners' language (Schachter 1988, 224), it is likely that this difficulty of appropriately managing focused information would be aggravated for learners. 
Cognitive linguistic approaches unanimously agree that the frequency of constructions in the language input positively impacts their acquisition, and that language acquisition is derived from and informed by language use (Langacker 1987; Ellis 2002; Tomasello 2003; Croft and Cruse 2004; Goldberg 2006; Ellis and Cadierno 2009). According to the usage-based approach adopted in this study, the frequency of use and learners' L1 have a profound impact on language acquisition. Slabakova (2015) proposed that the difficulties L2 learners face when dealing with the appropriate contextual use of optional noncanonical constructions are heightened if discourse-construction mapping differs in the frequency of occurrence across learners' L1 and the target language. With the exception of preposing, the focus constructions under investigation are not found in Arabic. This increases the interest in exploring whether frequency and learners' L1 impact Saudi learners' knowledge of these constructions (specifically preposing).

L2 users are said to have acquired the target constructions only if they have mastered both the appropriate contextual use of the target construction and the frequency distribution in the L2. However, it is unclear whether L2 users can successfully configure discourse-construction mapping and approximate the frequency with which different focus constructions are employed in the L2 across different discourse contexts, especially when only one of the target constructions is found in learners' L1. To address this issue, the current study explores whether English users of three proficiency levels (native speakers, L2 intermediate and L2 advanced) are sensitive to information structural constraints on focus constructions in English and to frequency differences between the target constructions.

This paper starts by presenting the theoretical background for the study, followed by the research questions and the methodology. Then, the results and discussion are presented. Finally, the paper ends with concluding remarks.

\subsection{Theoretical background of the study}

\subsubsection{Usage-based approach to language acquisition}

From a cognitive linguistics perspective, first language acquisition involves the acquisition of constructions that map linguistic form and function from language usage and experience with specific exemplars of constructions. In this sense, language is acquired from actual instances of language use in their full contextual understanding (Goldberg 1995; Langacker 2000; Ellis and Cadierno 2009).

According to usage-based approach, constructions can be acquired regardless of their length, with the process being strongly dependent on context and language users' communicative needs (Tomasello 2003). Further, abstract constructions (combinations of form and meaning) are argued to be learnt as generalisations over learnt instances of utterances (Langacker 1987; Olguin \& Tomasello 1993; Tomasello 2003). Usage-based approach views frequency of use as a fundamental factor in the process of learning L1(Langacker 1987; 
Tomasello 2003). Also, for learning an L2, there are usage-based approaches that build on the idea that frequency is an important factor (Ellis 2002, 2003; Slabakova 2015).

Usage-based approach to L2 acquisition holds that most of the processes involved in learning and developing an L1 are likely to be applied in learning an L2 as well, with the latter being associated with a further "layer of complexity" (Ellis \& Cadierno 2009: 12). Langacker (2005) argued that learners tend to learn the L2 in the same way as children learn their native language; the forms that they learn first and learn well are the forms that they frequently encounter. However, L2 acquisition is different from L1 acquisition in several aspects, such as L1 transfer and learned attention (Ellis 2008). A major difference for the L2 learner is that special categories of the L1 already exist in the mind of the language user (Ellis 2006). This suggests that L2 learners, especially at early stages, may transfer the L1 meanings to the process of form-meaning connections in their L2 (MacWhinney 1997; Langacker 2005; Ellis 2006). Lower proficiency L2 learners often have a tendency to construct form-meaning mappings in L2 based on their already established L1 constructions (Ellis 2002, 2005; Cadierno 2008). In this regard, the L1's influence on second language learners decreases as the learners build up L2 networks from increased exposure to L2 data (Ellis 2008).

Based on usage-based approach, language learners' attainment of nativelike knowledge of the conventional ways of using constructions comes about gradually through long-term practice with the target language. In the process of developing L2 knowledge, a U-shaped learning behaviour is likely to occur. This behaviour reflects the L2 users' tendency to overgeneralise (Ellis 2008). Further experience with the target language makes L2 learners more native-like and brings the curve 'up' again in the U-shape. As such, learners' attempts to overgeneralise are likely to be evident in higher levels of language proficiency (Taylor 1975:87; Ellis 2006; Robinson and Ellis 2008: 396).

This paper explores whether L2 speakers are sensitive to information structural constraints on focus constructions in English and to frequency differences between the target constructions. In this respect, the target constructions provide an ideal test bed for usage-based models of L2 acquisition because these low frequent syntactic options for information focusing share a similar discourse function while simultaneously differing in their occurrence frequency (Aleraini 2018).

\subsection{Focus constructions in English and Arabic}

Following a construction grammar framework, English focus constructions are viewed as carrying meaning independently of the words they contain (Goldberg 1995). The focus constructions under investigation are presented in the following examples (1b-e).

(1) a. The students read the introductory textbook.

(Canonical SVO)

b. It is the introductory textbook that the students read. (it-cleft) 
c. What the students read was the introductory textbook. (wh-cleft)

d. The introductory textbook was what the students read. ( $r w h$-cleft)

e. The introductory textbook the students read.

(preposing)

According to Lambrecht's $(1994,2001)$ analysis of information structure, the above sentences convey the same proposition. Nevertheless, each sentence in 1b-e packages the information differently without affecting the basic semantic structure of 1a. In this regard, the choice of using a focus construction in a communicative situation is pragmatically motivated, depending on the discourse context (Lambrecht 1994, 2001; Zimmerman and Onea 2011).

Hilpert (2014:181) argues that the use of cleft constructions is closely related to the activation of a pragmatic presupposition in the context. For example, some $w h$-questions permit special focus constructions to occur as an answer, and therefore 2a serves an information focus function (Kiss 1998). Consider the following example:

(2)What did you buy from the flower shop?

a. What I bought was a red rose.

b. It was a red rose that I bought.

One might find 2a more appropriate because it does not convey a notion of contrast like $2 \mathrm{~b}$. Although wh-cleft constructions take into account the speaker's assumption about the hearer's knowledge in the current context (activation), it can possibly occur in a situation with a semi-active pragmatic preposition. The wh-cleft explicitly indicates what is taken as background information (Biber et al. 1999:963). Unlike an it-cleft, a wh-cleft does not exhibit the pragmatic meanings of exclusiveness and/or exhaustiveness but rather expresses information focus (Callies 2009:57).It-clefts are commonly considered to be syntactic markers of contrast in English (Kiss 1998; Lambrecht 2001; Zimmerman and Onea 2011). Biber et al. (1999:962) argue that "It-clefts are typically contrastive; the contrast is often quite explicit". This feature makes the it-cleft appropriate in contexts where a pragmatic proposition is highly activated. To illustrate, if the question provided alternatives and only one is the correct answer, then the use of the it-cleft would be an appropriate answer in this context. For example:

(3) a. Did the student read the article or the textbook?

b. It was the textbook that the student read.

The reversed $w h$-cleft resembles an ordinary $w h$-cleft but with a different syntactic structure. The $w h$-clause is placed at the end of the sentence, while the element under focus is in the initial position. The reversed $w h$-cleft construction is similar to the it-cleft constructions since it also places the focus element in initial position. According to Callies (2008), wh-cleft construction serves to convey identificational focus. 
Preposing is broadly defined as a "sentence type in which a canonically post verbal phrase constituent appears in preverbal position" (Birner and Ward 1998:31). The most commonly preposed elements are nominal, often objects (Callies and Keller 2008:252). Functionally, preposing has been associated with contrastive emphasis (Kiss 1998; Chen 2003). Like the case with the it-cleft, preposing can be an appropriate answer to a question that presents alternative. For example:

(4) a. Did you fix your car or your bike?

b. My bike I fixed.

In Arabic, the non-canonical word order is the main feature of focus constructions as the focus element is preposed to occupy an initial position in a sentence (Al-Jurgani 1984). Functionally, the focus constructions dealt with in this study are of both the identificational focus and the information focus types.

As in English, changes in the basic word order in Arabic serve to express a particular meaning that cannot be properly conveyed through the basic word order (Suleiman 1989:216). Suleiman argues that "the function of utterances can't be judged solely by referring to their linguistic form" (1989:233). This thesis follows Suleiman's pragmatic approach by considering the functional aspects of Arabic structure when dealing with types of sentences.

Arabic allows two kinds of subject or object preposing to take place: obligatory and optional preposing. In obligatory preposing, the sentence meaning is not altered by preposing, nor does this type involve transformational movements, which often "call for a reinterpretation of language functions in a discourse perspective" (Suleiman 1989:219).

On the other hand, optional preposing changes the internal order of the sentence elements "to convey an additional meaning which would have been unattainable if the original order of the sentence elements, i.e. VSO, had not been changed into SVO, or OVS" (Suleiman 1989:222). Preposing the subject serves to bring a new topic into a discourse. For example,

$\begin{array}{lll}\text { S } & \text { V } & \text { O } \\ \text { Salimun } & \text { daraba } & \text { Kahlidan } \\ \text { Salim } & \text { hit } & \text { Kahlid }\end{array}$

'Salim hit Kahlid.'

Preposing the subject functions similarly to the canonical word order of Arabic (VSO) as they both follow the information flow principle (Biber et al. 1999:896). This principle refers to the distribution of information in a sentence. It holds that given or old information is presented in the sentence initial position followed by new information (Callies 2009:14) although this is not an unviolated principle (Callies 2009:14).

There are two optional object preposing constructions in Arabic: when an object precedes the subject of the sentence (VOS), and when the object precedes 
the verb occupying the initial position in the sentence (OVS). Suleiman describes optional object preposing as "a complex process which is realized through a movement transformation and based on some semantic, functional and discourse considerations that help interpret the enclosed message" (1989:330). He argues that optional object preposing in Arabic serves pragmatic functions, such as identification:

\begin{tabular}{lll} 
V & O & \multicolumn{1}{c}{ S } \\
daraba & Aliyyan & muhammadun \\
hit & Ali & Muhammad \\
'Muhammad hit Ali.' & & (Suleiman 1989:219)
\end{tabular}

In the above example that shows how identificational focus is conveyed in writing, the object Aliyyan receives more attention when placed before the subject Muhammad(Suleiman 1989:229) and when the nuclear pitch accent is assigned to the object once being uttered. More precisely, Aliyyan is optionally preposed to convey that Aliyyan and not anyone else was hit. In line with Suleiman (1989), Ouhalla (1999:338), argues that this preposing construction indicates the exclusion of other members involved in the discourse. He also points out that preposing in Arabic serves to contradict existing information (e.g. a speaker correcting a statement) and hence conveys identificational focus (1999:338). He uses the following illustrative example for an OVS sentence order with a negative continuation:

$$
\begin{array}{lcc}
\text { O } & \text { V } & \text { S } \\
\text { LAYLA } & \text { ashiqa } & \text { Qays-un } \quad \text { (la-ZAINAB) } \\
\text { Layla } & \text { loved-heQays-NOM (not Zainab-ACC) } \\
\text { "It was LAYLA that Qays loved (not Zainab)." (Ouhalla 1999, 338) }
\end{array}
$$

As shown above, the use of focus constructions related to object focus is infrequent in English and Arabic. English varies in the syntactic means to present focused information, while Arabic expresses focused information by placing the focused constituent in sentence initial position. In terms of frequency, the non-canonical word orders are restricted to information structural constraints.

\subsection{Empirical research on information highlighting in SLA research}

The few existing studies on focus construction are mainly interested in crosscultural investigation. A study by Zimmermann (2000) employed acceptability judgements to investigate the it-clefts and wh-clefts in German-English interlanguage. The results showed that learners' competence in the grammatical restrictions of these two types of clefts is not target-like. They also argued that there is an influence on L2 users from their L1 German indicating that advanced learners are not fully competent as to the grammatical restrictions of it-clefts and $w h$-clefts. 
Boström Aronsson (2003) investigated the use of the it-cleft and wh-cleft in argumentative writing of Swedish advanced learners of English. She found an over-representation of these constructions in the learners' data compared to native speakers' data. The author argued that the over-use of cleft constructions is likely explained by the fact that clefts are more commonly used in Swedish than in English, which makes them easily transferable to L2 English. The findings also indicated that it-cleft constructions are often used in the context where there is no obvious need to emphasise specific sentence constituents possibly because learners are not fully aware of the contextual effects of cleft constructions in English.

A study by Callies and Keller (2008) investigated the ability of a group of advanced L2 German learners to identify linguistic devices whenever they were used to highlight information in a text. The learners were asked to rewrite a poem as a prose text. Their findings showed that the advanced L2 users preferred lexical to syntactic means of information highlighting as they neither copied nor imitated the syntactic focusing devices used in the poem.

In a similar vein, Callies (2009) investigated the degree advanced L2 German learners resembled American native speakers in their knowledge and use of the means of information highlighting. Both groups were given a literary text in English and instructed to perform a discourse completion task and a pragmalinguistic judgement task. The findings indicated that advanced L2 learners have limited awareness of focus constructions. Callies found that the learners gave higher ratings for preposing and attributed this to a positive effect of $\mathrm{L} 1$, since a similar construction is used in German.

Interestingly, a case study by Farghal and Kalakh (2017)examined the translation of an Arab interpreter in order to see how he dealt with English focus constructions. The authors looked into the different types of focus constructions and their Arabic counterparts to investigate the translation procedures and evaluate how successful they were. They concluded that syntactic focusing devices, especially the it-cleft, are problematic structure for translators when translating into Arabic.

\subsection{Research questions and prediction}

The following questions guides the investigation:

1. Are L2 Saudi users of English and native speakers sensitive to the type of context (felicitous vs. infelicitous) in which the focus constructions are used?

2. Are L2 Saudi users of English and native speakers sensitive to the frequency distribution of the target constructions?

3. Does language proficiency (native speaker, advanced L2, intermediate L2) affect the users' knowledge of the target constructions?

Since information structure is part of the construction grammar (Lambrecht 1994:3), knowledge of these constructions requires an 
understanding of the ability to realise the fit between the use of these constructions in a felicitous context and their misfit in an infelicitous context. It is anticipated that discourse constraints, which license the use of focus constructions in the present study will affect participants' ratings of the target construction. It is also expected that L2 users and native speakers will detect discourse constraints that license the use of focus constructions, leading to higher acceptability rates for the target constructions in a felicitous context.

According to usage-based approach (Goldberg, 1995; Langacker, 2000; Ellis \& Cadierno, 2009), linguistic knowledge results from frequent exposure to incidents of the use of these constructions in the target language. As such, it is hypothesised that proficiency is likely to affect the rating of the target constructions. Moreover, since these constructions vary in their frequency of use in English, it is anticipated that the relatively more frequent constructions would receive higher acceptability rates (Biber et al. 1999).

For L2 acquisition, usage-based approach predict that L2 learners will experience difficulty in narrowing the use of focus constructions to appropriate discourse contexts particularly when constructions are not frequently used in the target language (Slabakova 2015). It is, therefore, expected that advanced L2 users will diverge from native speakers in their levels of acceptance of L2 focusing constructions, with the greatest divergence occurring with those constructions that are least frequent in the L2 input, such as reverse $w h$-cleft and preposing).

\section{Methodology}

\subsection{Participants}

Ninety-nine female participants from Princess Norah bint Abdulrahman University in Riyadh, Saudi Arabia were included in the final sample. They are divided into 35 L2 learners/users of intermediate proficiency level in English, 33 L2 learners/users of advanced proficiency users of English and31 native speakers of English. The L2 users were all Saudi with L1 Arabic and the native speakers were all British.

The intermediate L2 users were undergraduate students. Their age was between 18 and 20 years with a mean of $(M=18.20)$ and standard deviation of $(S D: 1.20)$. None of them had lived in an English-speaking country and none had knowledge of a third language. Based on the results of the online Oxford Placement Test, the intermediate proficiency learners were placed on B1 level of the Common European Framework of References for Languages (CEFR).Accordingly; this group has basic knowledge of English and hence is not expected to encounter the less frequent focus constructions in English.

The age of the advanced learners ranged between 22 and 30 years old $(\mathrm{M}=$ 26.31, $S D=2.24)$. The participants have had experience in teaching English at university level. They had all taken the IELTS and achieved scores of 7 to 8 , with an overall mean of $7.2(S D=1.30)$ out of a possible 9. Therefore, it was likely that they would have encountered constructions with low frequency of 
use, such as the focus constructions under investigation, due to their extensive exposure to the various constructions in English (R. Ellis 2008).

The native English speakers, who provided a native speaker baseline, were 28 to 38 years of age $(M=30.24, S D 4.21)$. They were all English teachers at the University's preparatory year program at the time of the study.

\subsection{Materials}

An acceptability rating task was designed based on insights from Lambrecht's (1994) account of information structure in English. Lambrecht has argued that language users' choice of information packaging constructions is related to the degree of activation of the pragmatic presupposition. In other words, speakers' adequate and successful choice of a particular information packaging construction is motivated by their assumptions about what hearers know (pragmatic presupposition) and what hearers need to figure out (pragmatic assertion) in a discourse.

The stimuli for the acceptability rating task consisted of 16 target items and 16 filler items. The target items consisted of eight contexts that evoke a felicitous use of the focus constructions and another eight that evoked an infelicitous use. Each context is followed by five responses: four focus constructions and a canonical word order sentence. The reason for including the latter is to serve as an acceptable response in situations where the use of the target constructions is considered a dis-preferred option, as in their use in the infelicitous context. The focused element in all the focus constructions is the object (patient) of the sentence. The constructions were presented in a randomised order to avoid promoting systematic answers (Dörnyei 2007).

In designing the appropriate contexts for the acceptability rating task, the activation of the pragmatic presupposition was considered together with communicative intentions, namely to correct or clarify a misunderstanding. The context included a question-answer format. In order to create suitable conditions for the use of focus constructions, an active pragmatic presupposition was evoked by questions eliciting a contrastive focus, which was the main interest in this study. Contrastive focus is elicited by the use of a question in which alternative/s are mentioned (Chafe 1976). This question comes in the form of Did you + V+ NP+ or + NP?

(8) You are in the kitchen washing some dishes and you accidently break a cup. You tell your mother that you broke a cup. Later she asks:

\section{- Did you say you broke a plate or a cup while you were washing the dishes? \\ -You say: ...}
a. It was a cup that I broke.
(it-cleft)
b. What I broke was a cup.
(wh-cleft)
c. A cup was what I broke.
(reverse $w h$-cleft) 

d. A cup I broke.
(preposing)
e. I broke a cup.
(canonical sentence)

In addition, an infelicitous condition for the use of the focus constructions was included. In this condition, no proposition between interlocutors was shared, resulting in an inactive pragmatic presupposition (Lambrecht 1994). The context created for this condition included a situation that used a direct (open) question that required new information as a response, and hence the use of the target constructions as a response was likely to be inappropriate.

(9) You go to a meeting and you realise that you have lost your phone. You go to the secretary's office. The office assistant says:

\section{- Can I help you?}

- You say: ...
a. It was a phone that I lost. (it-cleft)
b. What I lost was a phone. (wh-cleft)
c. A phone was what I lost. (reverse wh-cleft)
d. A phone I lost. (preposing)
e. I lost my phone. (canonical sentence)

As for the filler items, the contexts designed for them were questions that asked about the action that had taken place in the context and the responses to these questions differed in the verb tense employed. None of these responses consisted of any of the target constructions as shown in the example below.

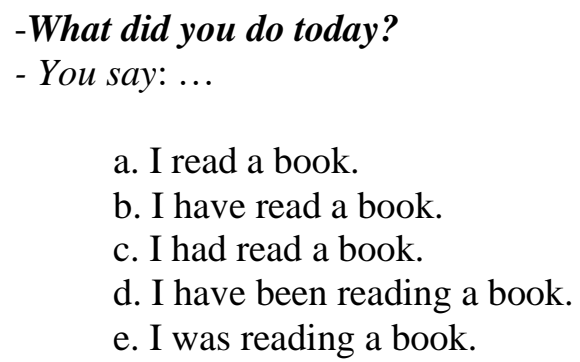

The filler items were included in order to: (1) avoid systematic responses; (2) distract the participants' attention from the purpose of the study; and (3) keep the participants actively engaged in the task until completed. The participants were instructed to rate the appropriateness of each response according to a 6-point Likert scale

\subsection{Procedure}

Participants were tested individually in a quiet room. They were asked to read the information sheet and sign a consent form before they started the test. The 
researcher informed each participant that they will receive a test consisting of 32 items each item has 5 statements and will be asked to rate the acceptability of these statement on a 6-point Likert scale. Participants first filled a language background questionnaire. Then they were asked to read the instructions and the example on how to perform the acceptability task. The participants were advised to carefully give their ratings and try to complete the task within 25 minutes. The test lasted approximately 20 minutes.

\section{Results}

The normality of the distribution of the scores on the acceptability rating task for each target construction was calculated for each group. All skewness and kurtosis ratios were within the acceptability range $( \pm 1.96)$, since there were small samples ( $\mathrm{N}<50$ in each group). This suggests no departure from normality. An initial data screening was a necessary step in order to select the appropriate statistical analysis to be performed on the data set (Pallant 2010).

\subsection{Felicitous context vs. Infelicitous context}

In order to answer the first research question, the participants' knowledge of the contextual use of the focus constructions was established by means of a pairedsamples $t$-test, comparing performance in the felicitous to the infelicitous context. The paired samplest-test was conducted to ascertain whether there were statistically significant differences in the participants' ratings of the focus constructions in the two types of contexts (Table 1). The results showed that there were statistically significant differences and large effect sizes in the three groups' rating of the it-cleft, wh-cleft and the reverse wh-cleft in the two types of contexts. The three participating groups gave higher ratings for all of these constructions in the felicitous context. However, there were no significant differences in the ratings of preposing in the two types of contexts between the native speakers and advanced L2 users, while intermediate L2 users gave higher ratings for preposing in the felicitous context.

Table 1. Paired-samples $t$-test results for native speakers' acceptability ratings of focus constructions in the felicitous and infelicitous context $(n=31)$

\begin{tabular}{|c|c|c|c|c|c|}
\hline (Low, high $)$ & \multicolumn{2}{|c|}{ Mean (SD) $95 \%$ CI } & \multicolumn{3}{|c|}{$p$ Cohen's } \\
\hline$i t$-cleft $(+)$ & $\begin{array}{l}1.73(1.2) \\
2.91\end{array}$ & $1.29,2.18$ & 7.99 & $<.001$ & \\
\hline it-cleft (-) & & & & & \\
\hline $\begin{array}{l}w h \text {-cleft }(+) \\
w h \text {-cleft }(-)\end{array}$ & $0.75(0.99)$ & $0.38,1.11$ & 4.19 & $<.001$ & 1.52 \\
\hline $\begin{array}{l}r w h \text {-cleft }(+) \\
r w h \text {-cleft }(-)\end{array}$ & $1.42(0.99)$ & $1.06,1.78$ & 8.01 & $001 \quad 2.9$ & \\
\hline
\end{tabular}




$$
\begin{array}{llllll}
\text { preposing }(+) & 0.08(0.60) & -0.08,0.24 & 1.00 & 0.32 & 0.37
\end{array}
$$

preposing $(-)$

Note. $(+)=$ felicitous context; $(-)$ =infelicitous context; $r w h$-cleft $=$ reversed $w h$-cleft; $\mathrm{L} 2=$ second language

Table 2. Paired-samples $t$-test results for advanced L2 users' acceptability ratings of focus constructions in the felicitous and infelicitous context $(n=31)$

\begin{tabular}{|c|c|c|c|c|c|}
\hline $\begin{array}{l}(\underline{\text { Low }, \text { high })} d \\
\text { it-cleft }(+) \\
\text { it-cleft }(-)\end{array}$ & $\begin{array}{l}\text { Mean (SD) } \quad 95 \% \text { CI } \\
1.30(1.43) 0.79,1.80\end{array}$ & 5.22 & $\begin{array}{l}t \\
<.001\end{array}$ & $\begin{array}{c}p \\
1.84\end{array}$ & Cohen's \\
\hline $\begin{array}{l}w h \text {-cleft }(+) \\
w h-\operatorname{cleft}(-)\end{array}$ & $1.24(1.56)-0.68,1.79$ & 4.57 & $<.001$ & 1.61 & \\
\hline $\begin{array}{l}r w h \text {-cleft }(+) \\
r w h \text {-cleft }(-)\end{array}$ & $1.85(1.30) 1.32,2.38$ & 7.08 & $<.001$ & 2.50 & \\
\hline $\begin{array}{l}\text { preposing }(+) \\
\text { preposing }(-)\end{array}$ & $0.20(0.69)-0.05,0.44$ & 1.63 & 0.11 & 0.57 & \\
\hline
\end{tabular}

Table3. Paired-samples $t$-test results for intermediate L2 users' acceptability ratings of focus constructions in the felicitous and infelicitous context $(n=31)$

\begin{tabular}{|c|c|c|c|c|c|c|}
\hline \multirow{2}{*}{\multicolumn{2}{|c|}{$\begin{array}{l}\text { Low, high }) d \\
\underline{\text { it-cleft }(+) 97}(1.17) 0.56,1.27 \\
\text { it-cleft }(-)\end{array}$}} & CI & & $t$ & $p$ & \multirow[t]{5}{*}{ Cohen's } \\
\hline & & 4.87 & $<.001$ & 1.67 & & \\
\hline $\begin{array}{l}w h \text {-cleft }(+) \\
w h \text {-cleft }(-)\end{array}$ & \multicolumn{2}{|l|}{$0.50(1.14) 0.11,0.89$} & 2.59 & 0.02 & 0.89 & \\
\hline $\begin{array}{l}r w h \text {-cleft }(+) \\
r w h \text {-cleft }(-)\end{array}$ & \multicolumn{2}{|l|}{$1.17(.86) 0.44,1.03$} & 5.08 & 0.01 & 1.74 & \\
\hline $\begin{array}{l}\text { preposing }(+) \\
\text { preposing }(-)\end{array}$ & \multicolumn{2}{|l|}{$0.29(0.58) 0.09,0.49$} & 2.99 & $<.001$ & 1.03 & \\
\hline
\end{tabular}


The following figures show that participants' ratings of the it-cleft, whcleft and reverse $w h$-cleft in the felicitous context were higher than the infelicitous context for the three participating groups. The ratings of preposing construction were higher only for intermediate L2 users.

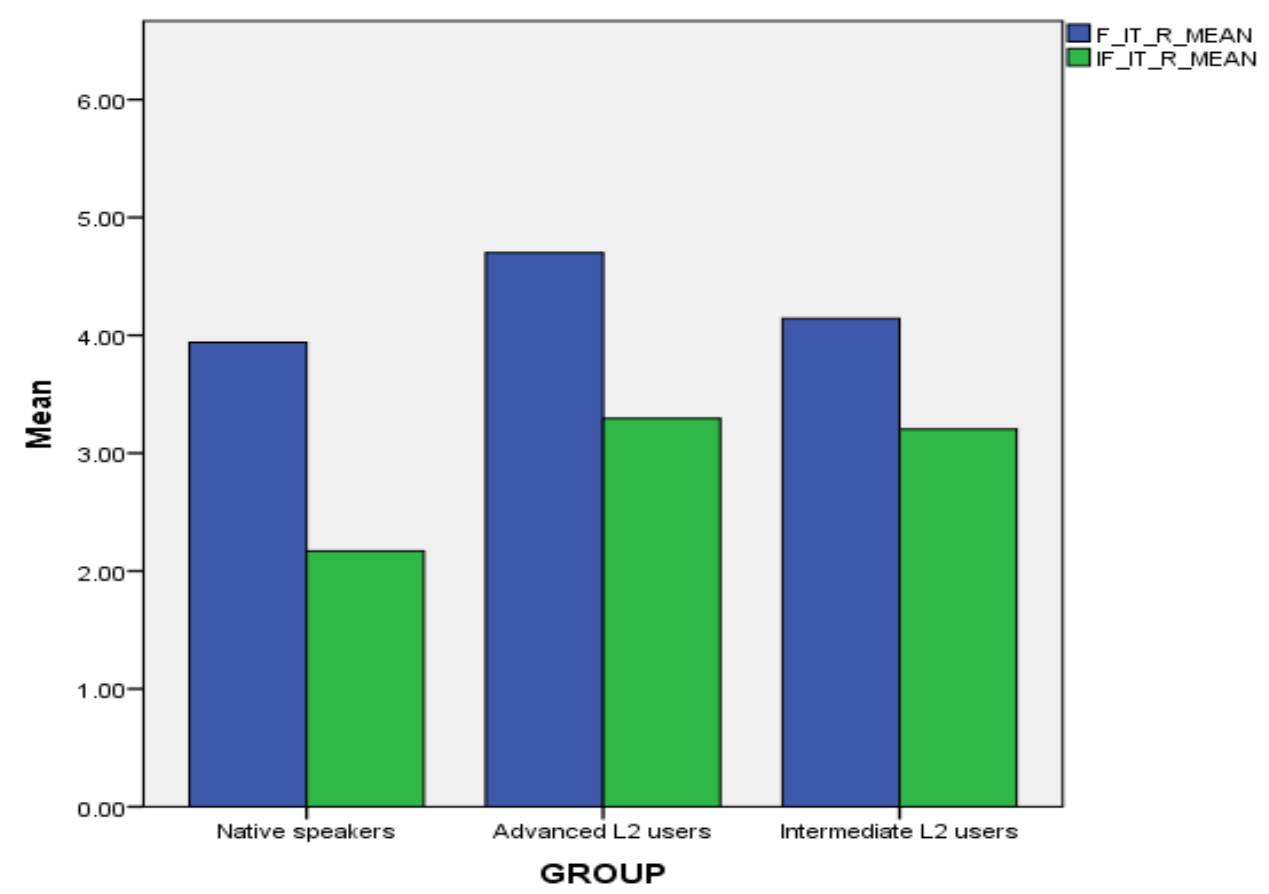

Figure 1. Ratings of it-cleft in the two contexts 


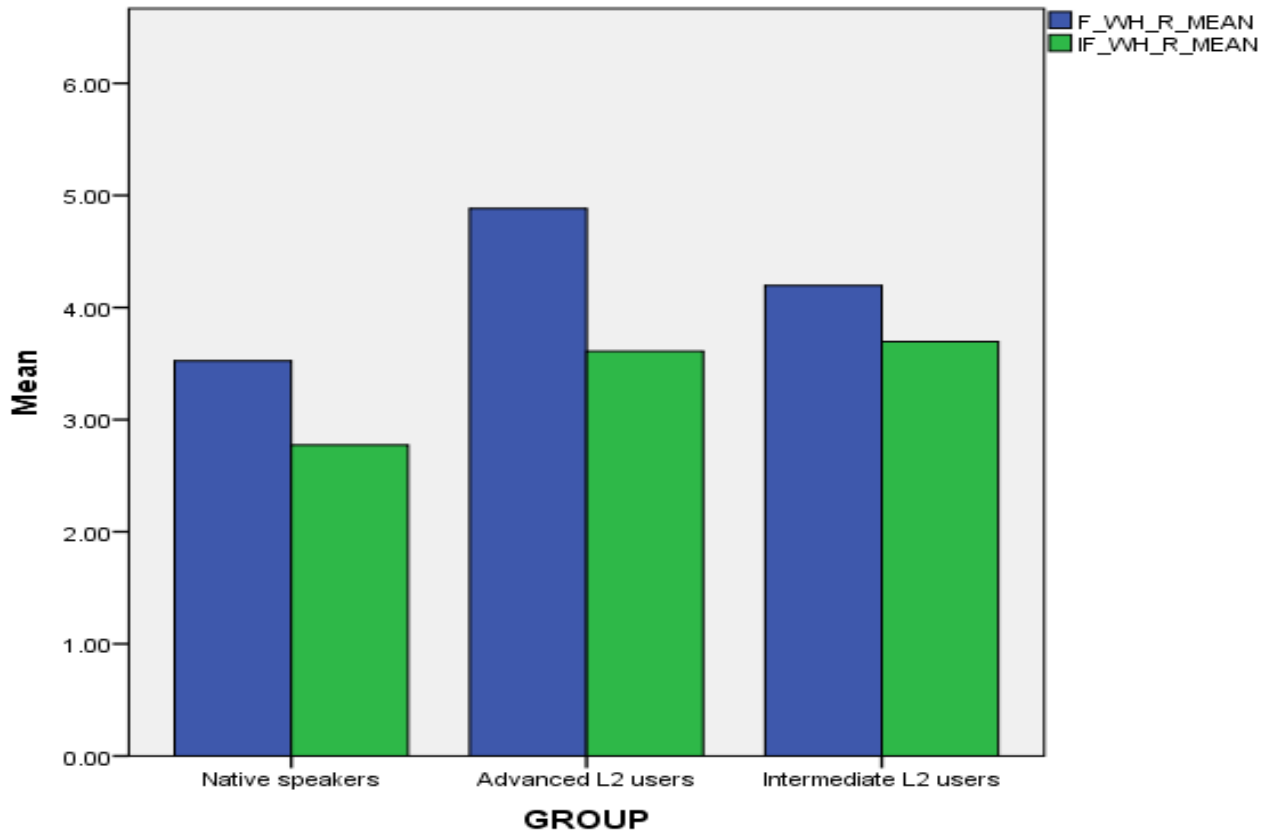

Figure 2. Ratings of wh-cleft in the two contexts

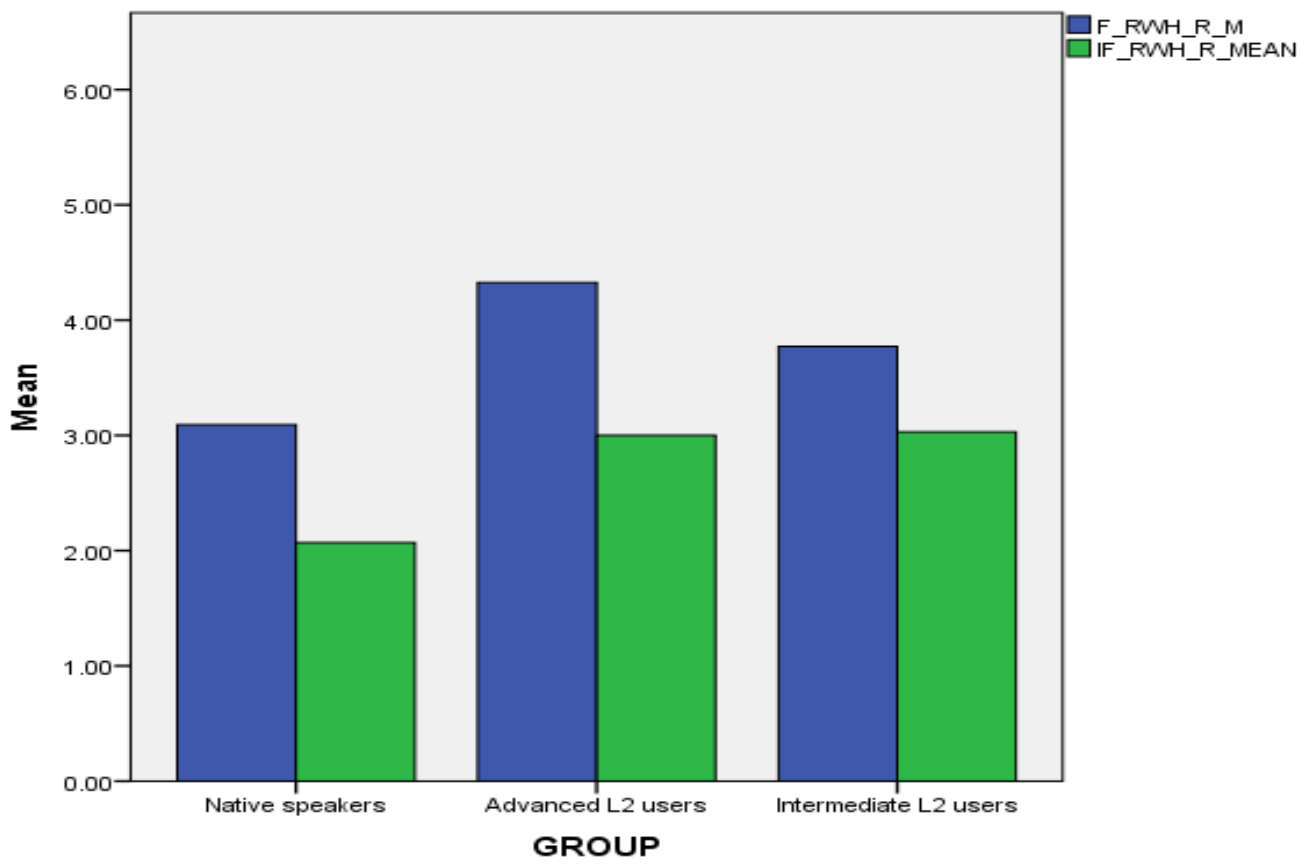

Figure 3. Ratings of rwh-cleft in the two contexts 


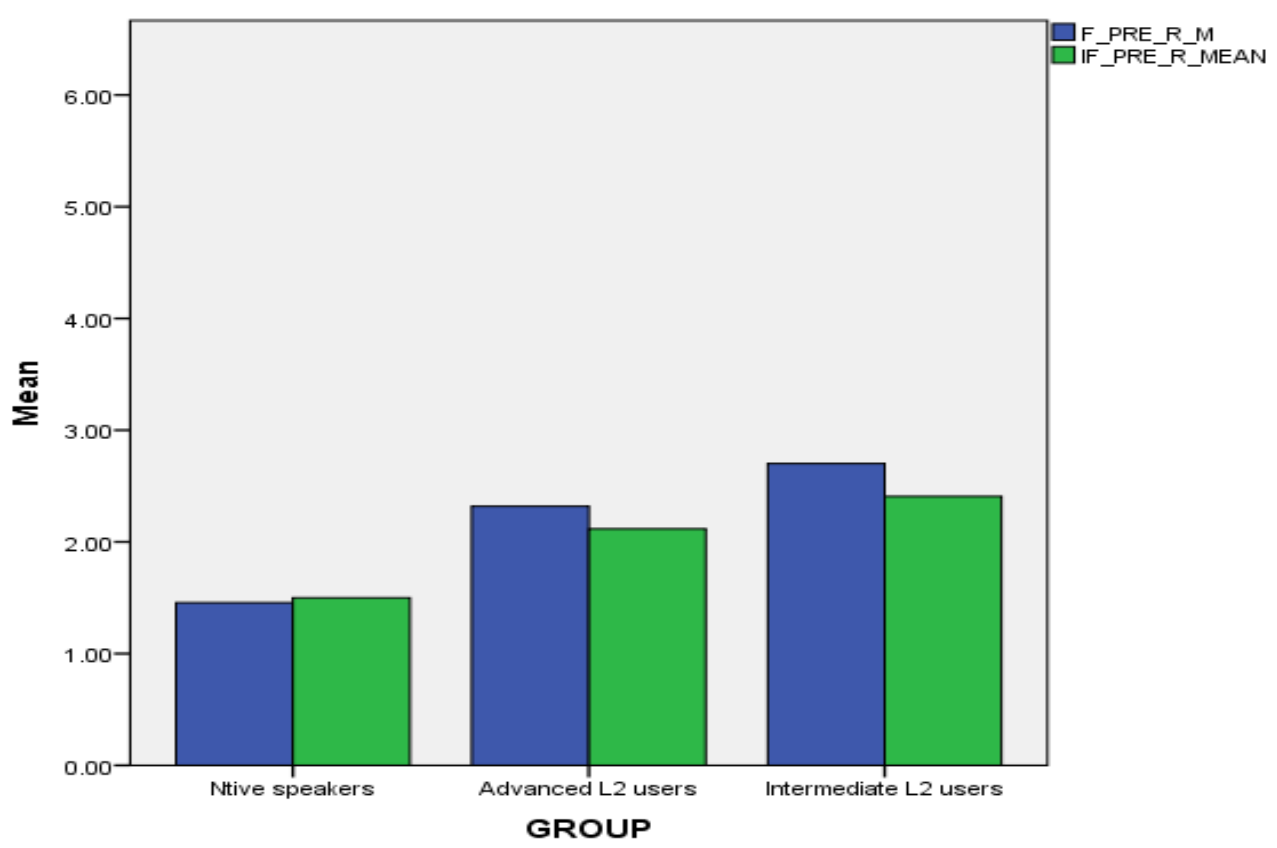

Figure 4. Ratings of preposing in the two contexts

\subsection{Within-group and between-group factors}

Participants' ratings of whether the focus constructions were acceptable responses to the question was the dependent variable and was submitted to a 2 (type of context) $\times 4$ (type of construction) $\times 3$ (proficiency groups) mixed ANOVA. Thereby, type of construction and context were within-participant factors while proficiency group was a between-participant factor. The assumption for Sphericity, which measures whether the differences between the dependent variances of a participant's data are equal (Larson-Hall 2010), was examined. The results indicated that Sphericity was not met. Therefore, the Greenhouse-Geisser correction was applied.

As shown in Table 4, the analysis of mixed ANOVA revealed significant main effects and a large effect size for Group and a significant main effect and a moderate effect size for both Construction and Context respectively. Also, significant interaction was observed between Construction and Context and this revealed a large effect size. Moreover, a significant threeway interaction and a medium effect size were observed between Group, Construction and Context. 
Table 4. Repeated measures analysis of variance ANOVA for the ratings of the focus constructions

\begin{tabular}{lcllll}
\hline Source & $d f$ & $F$ & $p$ & $\eta^{2}$ & Power \\
\hline Group & 2 & 12.92 & $<.001$ & 0.94 & 1.00 \\
Construction & 1.73 & 124.8 & $<.001$ & 0.60 & 1.00 \\
Context & 1.00 & 111.02 & $<.001$ & 0.54 & 1.00 \\
Group $\times$ Construction & 3.46 & 2.03 & 0.102 & 0.04 & 0.55 \\
Group $\times$ Context & 2.00 & 2.52 & 0.09 & 0.05 & 0.49 \\
Construction $\times$ Context & 2.40 & 40.97 & $<.001$ & 0.30 & 1.00 \\
Group $\times$ Construction $\times$ Context & 4.78 & 4.39 & $<.001$ & 0.09 & 0.96 \\
\hline
\end{tabular}

\subsection{Follow-up comparisons}

Follow-up comparisons by means of ANOVA and post-hoc comparisons with the Bonferroni correction were conducted for the ratings of each focus construction in the two types of context to determine where the differences between groups exist.

\section{It-cleft construction}

The ANOVA results for the ratings of the it-cleft construction revealed significant differences between groups and a large effect size in both the felicitous context $\left(F(2,96)=12.92, p=<.001, \eta^{2}=.94\right)$ and in the infelicitous context, $\left(F(2,96)=8.592, p<.001, \eta^{2}=.15\right)$. All groups gave higher ratings for this construction in the felicitous context. The post-hoc t-test with Bonferroni correction indicated that there were statistically significant differences between advanced L2 users and native speakers in the felicitous $(p=0.01)$ and infelicitous contexts $(p<.001)$. Significant differences were also found between advanced L2 users and intermediate L2 users $(p=.04)$ in the felicitous context but not in the infelicitous context $(p=0.73)$. However, there were no significant differences between native speakers and intermediate L2 users' ratings of the same construction in the felicitous context $(p=0.48)$, but significant differences were found in the infelicitous context $(p<.001)$.

Wh-cleft construction

The groups' ratings of the $w h$-cleft construction showed that there were statistically significant differences and a large effect size $(F(2,96)=9.936, p<$ $\left..001, \eta^{2}=.17\right)$ in the felicitous context and significant differences and a moderate effect size in the infelicitous context $\left(F(2,96)=4.967, p<.01, \eta^{2}=\right.$ .09). The results of the post-hoc Bonferroni test indicated significant differences between advanced L2 users and native speakers in the felicitous $(p<.001)$ and infelicitous contexts $(p<.001)$. Significant differences were also found between advanced L2 users and intermediate L2 users $(p=.02)$ in the felicitous context but not in the infelicitous context $(p=0.78)$, with advanced L2 users giving higher acceptability ratings. Moreover, there were significant differences between native speakers' and intermediate L2 users' ratings of the same 
construction in the felicitous context $(p=0.03)$ and in the infelicitous context ( $p$ $<.001)$. Native speakers gave lower acceptability ratings than intermediate L2 users.

Reverse wh-cleft construction

The analysis for the ratings of the reverse $w h$-cleft construction showed that there were statistically significant differences and large effect sizes in the felicitous context $\left(F(2,96)=8.424, p<.001, \eta^{2}=.15\right)$ and in the infelicitous context $\left(F(2,96)=8.424, p=.001, \eta^{2}=.17\right)$. The follow-up post-hoc Bonferroni test indicated that there were statistically significant differences between advanced L2 users and native speakers in the felicitous $(p<.001)$ and infelicitous contexts $(p<.001)$. However, no significant differences were found between advanced L2 users and intermediate L2 users in the felicitous context $(p=.06)$ or in the infelicitous context $(p=0.91)$. Significant differences were found between native speakers' and intermediate L2 users' ratings in the felicitous context $(p=0.02)$ and in the infelicitous context $(p<.001)$. As with the other constructions, native speakers gave lower acceptability ratings compared to the two L2 user groups.

\section{Preposing construction}

The comparison of preposing ratings showed that there were statistically significant differences and a large effect size $\left(F(2,96)=12.112, p<.001, \eta^{2}=\right.$ $.20)$ in the felicitous context and statistically significant differences and a moderate effect size in the infelicitous context $\left(F(2,96)=3.820(p<.05), \eta^{2}=\right.$ $.07)$. The post-hoc test using Bonferroni indicated that there were significant differences between advanced L2 users and native speakers in the felicitous ( $p<$ $.001)$ and infelicitous contexts $(p<.001)$. However, no significant differences were found between advanced L2 users and intermediate L2 users in the felicitous $(p=.14)$ or in the infelicitous context $(p=.18)$. Significant differences were found between native speakers' and intermediate L2 users' ratings of the same construction in both types of contexts $(p<.001)$.

The three-way interaction between Group, Construction and Context revealed statistically significant differences between the groups' ratings of the target constructions. The follow-up comparisons with post-hoc Bonferroni tests indicate that native speakers gave the highest ratings in the felicitous context for the $i t$-cleft, followed by the $w h$-cleft, then the $r w h$-cleft and lastly preposing. In the infelicitous context, there were significant differences between the wh-cleft and the it-cleft construction, with higher ratings for the $w h$-cleft. In contrast, the advanced L2 users' group gave the highest ratings for the $w h$-cleft, followed by the $i t$-cleft, then the reverse $w h$-cleft and lastly preposing in felicitous contexts. As for the intermediate L2 users, there were no significant differences in their ratings of the $i t$-cleft and the $w h$-cleft $(p=.84)$ in both types of contexts, as they gave higher ratings for these two constructions followed by the reverse $w h$-cleft and lastly preposing. Figures 5 and 6 illustrate the interaction between Group and Construction in the felicitous and infelicitous contexts respectively. 


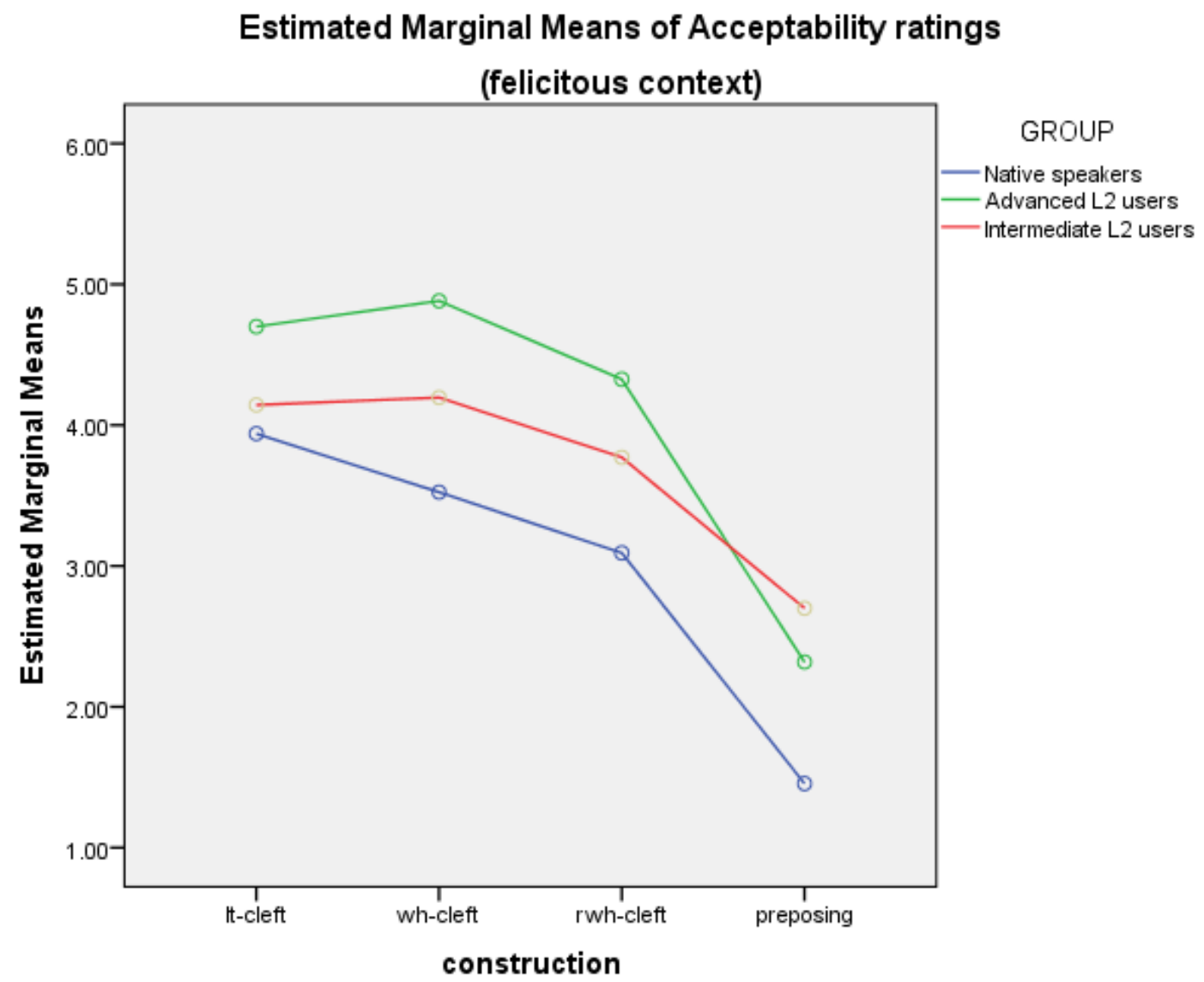

Figure 5. The ANOVA results of the interaction in acceptability ratings between Group and Construction in the felicitous context 


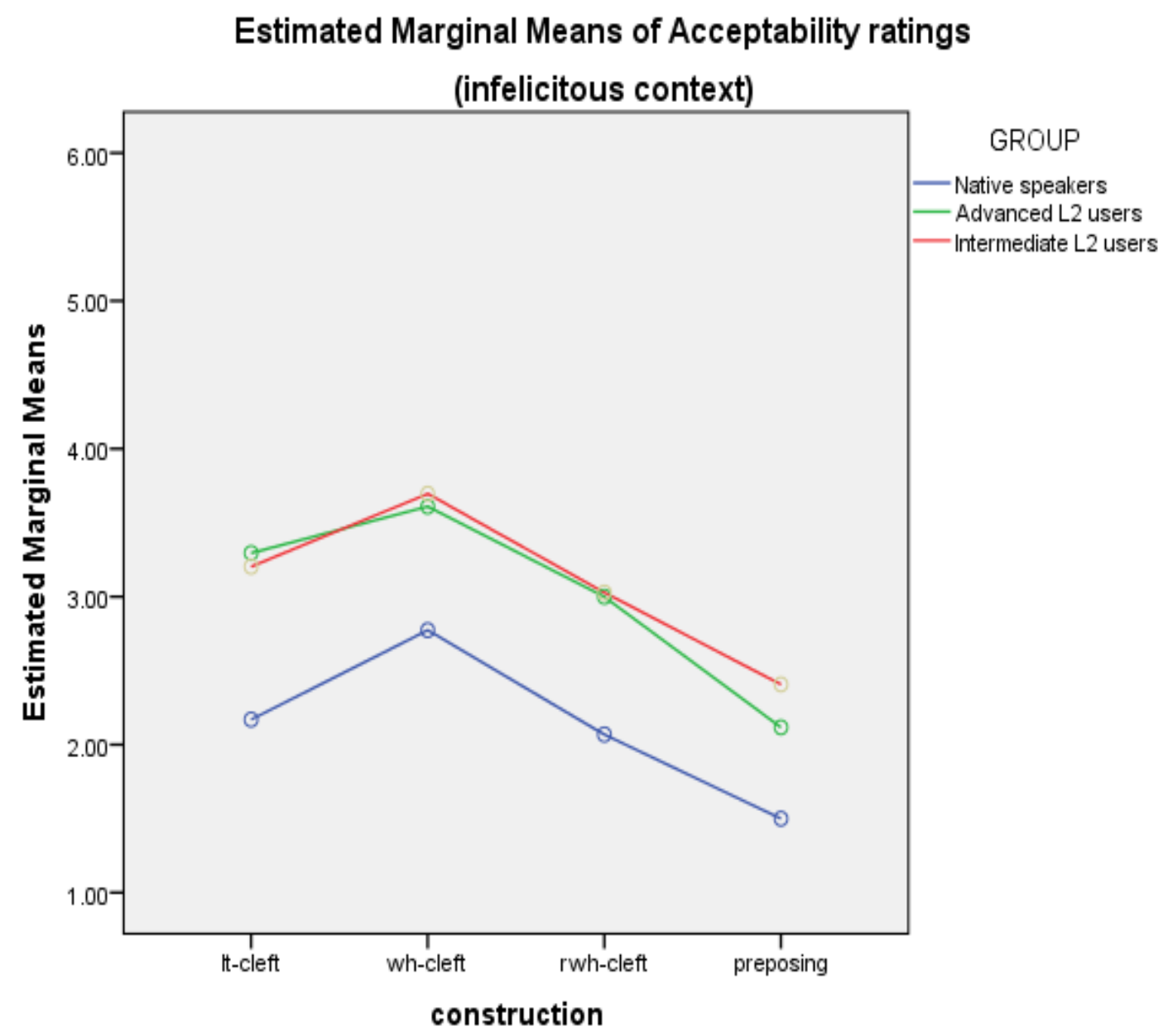

Figure 6. The ANOVA results of the interaction in acceptability ratings between Group and Construction in the infelicitous context

To sum up, the results of the participants' acceptability ratings indicated that proficiency level, type of construction and type of context had a statistically significant effect on the participants' acceptability ratings of English focus constructions.

\section{Discussion}

The present study probed how L1-English and L1-Arabic-L2-English speakers rate the acceptability of different types of focus constructions across different discourse contexts (felicitous vs. infelicitous context). It investigated whether L2 users are sensitive to the information-structural (IS) constraints that license the use of English focus constructions and to the frequency with which such constructions are used in the L2. It also explored the extent to which advanced 
L2 users are similar to native speakers in their knowledge of these constructions.

To address the first research question, I first explored whether participants are sensitive to the appropriate contextual use of the focus constructions, which is reflected in the ability of participants to appropriately map information structure function to form in English. The findings are in line with other studies documenting that such mapping does not constitute persistent difficulty in L2 acquisition (Robinson and Ellis 2008; Leal and Slabakova 2017; Hopp et al. 2018). However, there was no significant effect for context in the ratings of both native speakers and advanced L2 for preposing, as there were no significant differences between the two types of context. In other words, they found preposing to be inappropriate in both types of contexts.

For native speakers, this could be explained by the fact that the use of this construction is a dis-preferred option in the written mode and relatively rare in English (Odlin 1989:44; Waugh and Lafford 1994:2380; Callies 2009:51). As for advanced L2 users, the lack of contextual effect seems to indicate that they partly based their acceptability ratings on the formal feature of preposing, since there was a significant difference between their ratings and those of native speakers. Learners know from previous experience with the target language that the canonical word order of English is SVO. Realising that preposing has a different word order (OSV) could have made advanced L2 users consider it as an inappropriate option. According to VanPatten $(1990,1996)$, as the L2 linguistic knowledge develops through experience with the target language input, their focus shifts from meaning to the formal feature of the construction.

Interestingly, intermediate L2 users were the only group who showed sensitivity to the contextual effect when rating preposing. Unlike advanced L2 users, intermediate L2 users' performance seems to suggest that they have prioritised meaning over form to guide their interpretation (VanPatten 1990, 1996; Robinson and Ellis 2008). Another likely explanation relates to a possible L1 Arabic influence, as Arabic allows for the placement of the object (patient) of a sentence in initial-sentence position to direct attention to the most focal element in the sentence (Al-Jurgani 1984; Suleiman 1989:218). It has been argued that L2 users with lower proficiency in the target language are likely to transfer grammatical features from their source language to help them with learning the L2 (Ellis 2002, 2006; Ellis 2008:470).

Second, I turn to English users' sensitivity to frequency differences in the use of the target constructions by comparing their ratings for each target construction with those of native speakers. The results of the repeated measures ANOVA revealed a significant main effect for type of construction and the pairwise comparisons indicated that, apart from intermediate L2 users in it-cleft and wh-cleft constructions, the three groups gave significantly different acceptability ratings for different constructions in the felicitous context. Generally, the findings indicate that all participants gave higher acceptability ratings to the reasonably recurrent constructions (it-cleft and wh-cleft) compared to the comparatively less frequent constructions (reverse wh-cleft and 
preposing). Native speakers gave the highest ratings to the it-cleft followed by the $w h$-cleft then the reverse $w h$-cleft and lastly preposing. The higher acceptability ratings for the $i t$-cleft could relate to the fact that the felicitous context in this study evoked a contrastive focus strongly associated with the $i t$ clefts and less so for the wh-clefts in English (Biber et al. 1999, 962; Givón 2001: 225; Kiss 1998: 250; Ward et al. 2002). Fronting the focused element within the it-cleft gives it an emphasising effect, which is less salient in the $w h$ cleft. This emphasis relates to the idea that it-clefts carry contrastive focus, which facilitates the identification of an appropriate alternative that best refers to the asserted constituent in the utterance and excludes the remaining alternatives. For example:

(11) Did you say you read a book or a magazine?

a. It was a book that I read.

b. What I read was a book.

Here, the question requires the selection of one of the two alternatives. This process of selecting one of the alternatives over another conveys a contrastive focus, which involves the activation of the pragmatic presupposition (Lambrecht 2001). This feature makes the it-cleft appropriate in contexts in which a pragmatic proposition is highly activated, as in the example above, more so than the $w h$-cleft. Lambrecht (2001) argued that the difference between the $i t$-cleft and the $w h$-cleft largely depends on the activation of the pragmatic presuppositions in a discourse. This makes the use of the it-cleft more appropriate in the felicitous context, and hence explains native speakers' higher ratings.

The advanced L2 users gave the highest ratings to the $w h$-cleft followed by the it-cleft, then the reverse $w h$-cleft and lastly preposing. A likely explanation for the high acceptability ratings for the $w h$-cleft could relate to the fact that this construction has a canonical word order, which is absent from the rest of the focus constructions. This suggests that advanced L2 users prefer sentence types that are similar to those they have encountered in their previous experience with the target language (Mitchell et al. 1995). Another possible explanation could be related to the fact that the construction can be used in other contexts such as serving discourse-management functions (Hopper 2001; Kim 2002) as in disagreement and repair illustrated through the examples What I said was/What I meant was ... respectively (Kim 1995). In both possibilities, the findings seem to imply that $\mathrm{L} 2$ users relied on their previous experience with the target language, which is in line with the usage-based approach to language acquisition (Goldberg, 1995; Ellis 2002, 2005). However, advanced L2 users' high ratings compared to those of native speakers seem to signal a tendency for generalisation, which in turn is likely to be indicative of their limited knowledge of the wh-cleft construction as a syntactic focusing device in English. The result is in line with Rowley-Jolivet and Carter-Thomas's (2005) claim that even in the advanced stages, L2 users tend to show insufficient knowledge of the 
functions of wh-clefts, particularly when they serve as an informationhighlighting device. According to usage-based approaches, the inconsistent mapping of form and function (i.e., the same form (wh-cleft) serves different functions) is likely to cause difficulty in learning linguistic constructions (Goldberg, 1995; Ellis 2002, 2005). As such, it could be that the different functions for the wh-cleft in English could have caused advanced L2 users to have limited knowledge of its appropriate use as a focusing device, as evident from their high acceptability ratings.

Remarkably, intermediate L2 users considered the wh-cleft construction to be equally appropriate as the it-cleft construction in the felicitous context followed by the reverse $w h$-cleft and lastly preposing. The fact that there were no significant differences in the acceptability ratings of the it-cleft and the whcleft constructions likely suggests that intermediate L2 users have limited knowledge of the preferred option of focusing device in English. Moreover, the formal feature of these constructions is likely to have caused intermediate L2 users to correctly interpret its discourse functional use and hence rate it as acceptable. According to VanPatten (1990, 1996), L2 users, particularly in the early stages of proficiency, tend to process input for meaning.

Lastly, the results of the effect of proficiency on the users' knowledge of focus constructions showed that different proficiency groups had different views regarding the appropriateness of the use of each of the focus constructions in both types of contexts. This signals a role for proficiency in the comprehension of the target construction. This is supported by the results obtained from the repeated measures ANOVA, which revealed a significant main effect for groups. The results are in line with the usage-based approach, which assumes that linguistic knowledge is driven from language users' experience with the target language (Ellis 2002).

Generally speaking, the pairwise comparisons indicated that acceptability ratings for the target constructions by L2 users were significantly higher than native speakers. The over-acceptance of the focus constructions seems to signal a tendency for generalisation, likely indicative of their limited knowledge of the target constructions as a syntactic focusing device in English (Ellis 2001, 2003; Langacker 2005; Aleraini 2018).

\section{Conclusion}

Following a usage-based constructionist approach, the findings of this study revealed that L2 users are sensitive to information structure constraints on the use of focus constructions related to object. The results also provided novel evidence suggesting that L2 users are sensitive to the frequency with which focus constructions are used in the L2, even when these constructions are not very frequent in L2 input. At the same time, the over-acceptance of the focus constructions among both groups of L2 suggests that L2 users are not fully competent in the appropriate use of the target constructions, which is likely due to insufficient incidents of the use of the target construction in the target language input. Therefore, the results support the usage-based approach, which 
assumes that linguistic knowledge is driven by language users' experience with the target language (Ellis 2002, 2005). In addition, the results presented evidence of the fact that L2 users gradually construct their system of L2 representation over a considerable period of time and language use (Robinson and Ellis 2008, 8).

Nadiah Aleraini

Department of Linguistics

Princess Nourah bint Abdulrahman University, KSA

Email: n.orainy1@gmail.com 


\section{References}

Abdul-Hafiz, Ahmed-Sokarno. (2005). 'Verb agreement in SA: An analysis in the minimality program'. Journal of Language and Linguistics, 4 (1): 100-120.

Al Eraini, Nadiah. (2018). Investigating Focus Constructions in an EFL Context: a usage-based Approach. Unpublished PhD Thesis, Lancaster University: UK.

Al-Jurgani, Abdalqahır. (1984). Dala'il Al-igjaz. verified by M. Rashid Rida, Dar AI-m and aarif, Beirut.

Biber, Douglas, Stig Johansson, Geoffrey Leech, Susan Conrad, and Edward Finegan. (1999). Longman Grammar of Spoken and WRITTEN English. Harlow, UK: Pearson Education.

Birner, Betty. J., and Gregory. Ward. (1994). 'Uniqueness, familiarity, and the definite article in English'. BLS, 20: 93-102.

Boström Aronsson, M. (2003). 'On clefts and information structure in Swedish EFL writing'. In Extending the Scope of Corpus-Based Research. New Applications, New Challenges, S. Granger and S. Petch-Tyson, 197-210). Amsterdam: Rodopi.

Cadierno, Teresa. (2008). 'Learning to talk about motion'. In Handbook of Cognitive Linguistics and Second Language Acquisition, edited by P. Robinson and N. C. Ellis, 239-75. New York: Routledge.

Callies, Marcus, and Wolfram Keller, W. (2008). 'The teaching and acquisition of focus constructions: An integrated approach to language awareness across the curriculum'. Language Awareness, 17 (3): 249-266.

Callies, Marcus. (2009). Information Highlighting in Advanced Learner English. Amsterdam: John Benjamins.

Carroll, Mary, Jorge Murcia-Serra, Marzena Watorek, and Allessandra Bendiscoli. (2000). 'The relevance of information organisation to second language acquisition studies: The descriptive discourse of advanced adult learners of German'. Studies in Second Language Acquisition, 22: 441466.

Chafe, Wallace. (1976). 'Givenness, contrastiveness, definiteness, subject, topic, and point of view". In Subject and Topic, edited by C.N. Li, 25-55. New York: Academic Press.

Chen, Rong. 2003. English Inversion: A Ground-Before-Figure Construction. Berlin, New York: Mouton de Gruyter. 
Chen, Rong. (2013). Subject Auxiliary Inversion and Linguistic Generalization: Evidence for Functional/Cognitive Motivation in Language. Berlin, New York: Mouton de Gruyter.

Cohen, Jacob. (1988). Statistical Power Analysis for the Behavioral Sciences (2nd ed.). Hillsdale, NJ: Erlbaum.

Croft, William. (2001). Radical Construction Grammar: Syntactic Theory in Typological Perspective. Oxford: Oxford University Press.

Croft, William, and D. Alan Cruse. (2004). Cognitive Linguistics. Cambridge: Cambridge University Press.

Dörnyei, Zoltan. (2007). Research Methods in Applied Linguistics: Quantitative, Qualitative and Mixed Methodologies. Oxford: Oxford University Press.

Ellis, Nick C. (2001). Memory for language. In Cognition and Second Language Instruction, edited by P. Robinson, 33-68. Cambridge: Cambridge University Press.

Ellis, Nick C. (2002). 'Frequency effects in language acquisition: A review with implications for theories of implicit and explicit language acquisition'. Studies in Second Language Acquisition, 24: 143-188.

Ellis, Nick C. (2003). 'Constructions, chunking, and connectionism: The emergence of second language structure'. In Handbook of Second Language Acquisition, edited by C. Doughty and M. H. Long, 33-68. Oxford: Blackwell.

Ellis, Nick C. (2005). 'At the interface: Dynamic interactions of explicit and implicit language knowledge'. Studies in Second Language Acquisition, 27: 305-352.

Ellis, Nick C. 2006. Cognitive perspectives on SLA: The associative cognitive CREED. AILA Review, 19: 100-121.

Ellis, Nick C., and TeresaCadierno. (2009). 'Constructing a second language: Introduction to the special section'. Annual Review of Cognitive Linguistics, 7: 111-139.

Ellis, Rod. (2008). The Study of Second Language Acquisition. Oxford: Oxford University Press.

Farghal, Mohammad, and Bushra Kalakh. (2017). 'English Focus

Structures in Arabic Translation: A Case Study of Gibran's The Prophet'.

International Journal of Arabic- English studies, 17: 233-251

George, Darren, and Paul, Mallery. (2003). SPSS for Windows Step by Step: A Simple Guide and Reference. 11.0 update,4th ed. Boston, MA: Allyn \& Bacon. 
Givón, Tamly. (2001). Syntax: An Introduction, vol. I. Amsterdam, Philadelphia, PA: John Benjamins. (New Edition of Syntax: A Functional-Typological Introduction, 1984).

Goldberg, Adele. (1995). Constructions: A Construction Grammar Approach to Argument Structure. Chicago, IL: University of Chicago Press.

Goldberg, Adele. (2006). Constructions at Work: The Nature of Generalization in Language. Oxford: Oxford University Press.

Hilpert, Martin. (2014). Construction Grammar and Its Application to English. Edinburgh: Edinburgh University Press.

Hopp, Holger. (2009). 'The syntax-discourse interface in near-native L2 acquisition: Off-line and on-line performance'. Bilingualism: Language and Cognition, 12: 463-483.

Hopp, Holger, Joseph Bail, and Carrie N. Jackson. (2018). 'Frequency at the syntax-discourse interface: A bidirectional study on fronting options in L1/L2 German and L1/L2 English. Frequency at the syntax-discourse interface: A bidirectional study on fronting options in L1/L2 German and L1/L2 English'. Second Language Research, 36 (1): 65-96 https://doi.org/10.1177/0267658318802985

Hopper, Paul. J. (2001). 'Grammatical constructions and their discourse origins: Prototype or family resemblance?'. In Applied Cognitive Linguistics I: Theory and Language Acquisition, edited by Martin Pütz, Susanne Niemeier, and Rene Dirven, 109-29. Berlin/New York: Mouton de Gruyter.

Kim, Albert E., Srinivas, Bangalore, and Trueswell, John. C. (2002). 'The convergence of lexicalist perspectives in psycholinguistics and computational linguistics'. In P. Merlo and S. Stevenson (Eds.), The Lexical Basis of Sentence Processing: Formal, Computational, and Experimental Perspectives (pp. 109-35). Philadelphia: Benjamins.

Kiss, Katalin. (1998). ' Identificational focus versus information focus'. Language 74: 245-73.

Lambrecht, Knud. (1994). Information Structure and Sentence Form: Topic, Focus, and the Mental Representation of Discourse Referents. Cambridge: Cambridge University Press.

Lambrecht, Knud. (2001). A framework of the analysis of cleft-constructions. Linguistics 39: 463-516.

Langacker, Ronald. 1987. Foundation of Cognitive Grammar. Vol.1: Theoretical Prerequisites. Stanford, CA: Stanford University Press.

Langacker, Ronald W. (2000). 'Virtual reality'. Studies in the Linguistic Sciences, 29: 77-103. 
Langacker, Ronald W. (2005). 'Dynamicity, fictivity, and scanning: The imaginative basis of logic and linguistic meaning'. In Grounding Cognition: The Role of Perception and Action in Memory, Language, and Thinking, edited by R. A. Zwaan and D. Pecher, 164-97. Cambridge: Cambridge University Press.

Larson-Hall, Jenifer. (2010). A Guide to Doing Statistics in Second Language Research Using SPSS. New York: Routledge.

Leal, Tania, and Roumyana Slabakova. (2017). 'The relationship between L2 instruction, exposure, and the L2 acquisition: a syntax-discourse property in L2 Spanish. Language Teaching Research'. Electronic publication ahead of print version. Published online: 17 December 2017 (doi: 10.1177/1362168817745714).(Retrieved on 2 March,2013)

MacWhinney, Brian. (1997). 'Second language acquisition and the competition model'. In A. M. B. de Groot \& J. F. Kroll (Eds.), Tutorials in Bilingualism: Psycholinguistic Perspectives (pp. 113-144). Mahwah, NJ: Erlbaum.

McLaughlin, Barry. (1990). 'Restructuring'. Applied Linguistics, 11: 113-28.

Mitchell, Don C., Fernando Cuetos, Martin M. B. Corley, and Marc Brysbaert (1995). 'Exposure-based models of human parsing: Evidence for the use of coarse-grained (nonlexical) statistical records'. Journal of Psycholinguistic Research, 24, 469-88.

Odlin, Terence. (1989). Language Transfer: Cross-Linguistic Influence in Language Learning. Cambridge: Cambridge University Press.

Ouhalla, Jamal. (1999). 'Focus and Arabic clefts'. In The Grammar of Focus, edited by G. Rebuschi and L. Tuller, 335-59. Amsterdam, Philadelphia, PA: John Benjamins.

Pallant, Julie. (2010). SPSS Survival Manual: A Step by Step Guide to Data Analysis Using SPSS. Maidenhead: Open University Press/McGraw-Hill.

Robinson, Peter, and Nick C. Ellis. (2008). 'Conclusion: Cognitive linguistics, second language acquisition and instruction - Issues for research'. In $A$ Handbook of Cognitive Linguistics and SLA, edited by Peter Robinson and Nick C. Ellis, Chapter 19. London: Routledge.

Rowley-Jolivet, E. and S. Carter-Thomas. (2005). 'Genre awareness and rhetorical appropriacy: Manipulation of information structure by NS and NNS scientists in the international conference setting'. English for Specific Purposes, 24: 41-64.

Schachter, Jacquelyn. (1974). 'Second language acquisition and its relationship to Universal Grammar'. Applied Linguistics, 9, 219-235 
Slabakova, Roumyana. (2015). 'The effect of construction frequency and native transfer on second language knowledge of the syntax-discourse interface'. Applied Psycholinguistics, 36: 671-699.

Sorace, Antonella. (2011). 'Cognitive advantages in bilingualism: Is there a “bilingual paradox”? '. In P. Valore (ed.) Multilingualism. Language, Power, and Knowledge, 335-358. Pisa: Edistudio.

Suleiman, Saleh. (1989). 'A relationally-based study of subject-object properties in Standard Arabic'. Arab Journal of Language Studies 4: 13350.

Taylor, Barry. P. (1975). 'Adult language learning strategies and their pedagogical implications'. TESOL Quarterly, 9: 391-99.

Tomasello, Michael. (2003). Constructing a Language: A Usage Based Theory of Language Acquisition. Cambridge, MA: Harvard University Press.

VanPatten, Bill. (1990). 'Attending to content and form $m$ the input: An experiment in consciousness'. Studies in Second Language Acquisition, 12: 287-301.

VanPatten, Bill, and Soile Oikkenon.(1996). 'Explanation versus structured input in processing instruction'. Studies in Second Language Acquisition, 18: 495-510.

Ward, G., B. Birner, and R. Huddleston. (2002). Information packaging. In The Cambridge Grammar of English Language, edited by R. Huddleston, 1363-448). Cambridge: Cambridge University Press.

Ward, Gregory and Ellen, Prince. (1991). 'On the Topicalization of Indefinite NPs'. Journal of Pragmatics, 16: 167-177.

Waugh, Linda, and Barbara Lafford. (1994).'Markedness'. In The Encyclopedia of Language and Linguistics, edited by R. E. Asher and J. M. Y. Simpson, 2378-83. Oxford: Pergamon Press.

Zimmermann, Malte. (2000). 'Pluractional quantifiers: the occasionalconstruction in English and German'. In Brendan Jackson and Tanya Matthews, eds., Proceedings of SALT X, 290-306. Ithaca, NY: Cornell University.

Zimmermann, Malte, and Edgar Onea. (2011). 'Focus marking and focus interpretation'. Lingua, 121: 1651-70. 